\title{
Long-term effects of mowing on plasticity and allometry of Leymus chinensis in a temperate semi-arid grassland, China
}

\author{
LI Xiliang $^{1}$, HOU Xiangyang ${ }^{*}$, REN Weibo ${ }^{1}$, Taogetao BAOYIN ${ }^{2 *}$, LIU Zhiying ${ }^{2}$, Warwick \\ BADGERY $^{3}$, LI Yaqiong ${ }^{2}$, WU Xinhong ${ }^{1}$, XU Huimin ${ }^{2}$ \\ ${ }^{1}$ National Forage Improvement Center, Key Laboratory of Grassland Resources and Utilization of Ministry of Agriculture, \\ Institute of Grassland Research, Chinese Academy of Agricultural Sciences, Hohhot 010010, China; \\ ${ }^{2}$ Ecology, College of Life Sciences, Inner Mongolia University, Hohhot 010021, China; \\ ${ }^{3}$ New South Wales Department of Primary Industries, Orange Agricultural Institute, Orange, New South Wales 2800, Australia
}

\begin{abstract}
Mowing is an important land management practice for natural semi-arid regions. A growing body of empirical evidence shows that different mowing regimes affect the functioning of grassland ecosystems. However, the responses of plant functional traits to long-term mowing and their allometric scaling under long-term mowing are poorly understood. For a better understanding of the effects of mowing on grassland ecosystems, we analyzed the allometric traits of leaves and stems of Leymus chinensis (Trin.) Tzvel., a dominant grass species in eastern Eurasian temperate grassland, at different mowing intensities (no clipping, clipping once every two years, once a year and twice a year). Experiments were conducted on plots established over a decade ago in a typical steppe of Xilinhot, Inner Mongolia, China. Results showed that most of the functional traits of $L$. chinensis decreased with the increased mowing intensity. The responses of leaves and stems to long-term mowing were asymmetric, in which leaf traits were more stable than stem traits. Also significant allometric relationships were found among most of the plant functional traits under the four mowing treatments. Sensitive traits of L. chinensis (e.g. leaf length and stem length) were primary indicators associated with aboveground biomass decline under high mowing intensity. In conclusion, the allometric growth of different functional traits of $L$. chinensis varies with different long-term mowing practices, which is likely to be a strategy used by the plant to adapt to the mowing disturbances.
\end{abstract}

Keywords: Leymus chinensis; allometry; plant functional traits; mowing; semi-arid grassland; Inner Mongolia

Citation: LI Xiliang, HOU Xiangyang, REN Weibo, Taogetao BAOYIN, LIU Zhiying, Warwick BADGERY, LI Yaqiong, WU Xinhong, XU Huimin. 2016. Long-term effects of mowing on plasticity and allometry of Leymus chinensis in a temperate semi-arid grassland, China. Journal of Arid Land, 8(6): 899-909. doi: 10.1007/s40333-016-0005-z

Leymus chinensis (Trin.) Tzvel., widely distributed across eastern Eurasian temperate regions, is a dominant species of the grasslands of the Inner Mongolian steppe, which have been traditionally used as rangelands for both livestock grazing and haymaking (Wu, 1980; He et al., 2008). It is a normal practice in the semi-arid regions of Inner Mongolia in northern China to clip grassland every year without applying any fertilizer (Baoyin et al., 2014). A growing body of empirical evidence suggests that grassland ecosystems are affected to different extents by different mowing regimes (Han et al., 2007; Herrero-Jáuregui et al., 2014), but the differences have not been studied for L. chinensis. The changes in the functional traits of $L$. chinensis as a dominant species

*Corresponding authors: HOU Xiangyang (E-mail: houxy16@126.com); Taogetao BAOYIN (E-mail: bytgt@sohu.com)

Received 2015-12-06; revised 2016-05-01; accepted 2016-05-10

(C) Xinjiang Institute of Ecology and Geography, Chinese Academy of Sciences, Science Press and Springer-Verlag Berlin Heidelberg 2016 
are likely to indicate the changing stages of the grassland ecosystem processes.

Mowing in arid and semi-arid natural grasslands affects the properties and processes of ecosystems (Baoyin et al., 2014). Long-term mowing of plants can change the temperature and carbon content of the soil, which in turn change soil properties, such as respiration (Zhou et al., 2007; Baoyin et al., 2014). In the last 50 years, the productivity of grassland ecosystems has declined, reducing the vital roles they could play in hydrology, biodiversity and carbon cycling (Li et al., 2012). Grasslands are experiencing increasing levels of anthropogenic disturbances, including mowing, which have caused significant modifications to grassland communities, such as loss of biodiversity and changes of structures of ecosystems. However, few empirical studies have been conducted to explicitly examine how the traits of the typical-steppe grassland plants in northern China respond to different land-use practices, particularly mowing (Baoyin et al., 2014; Moreno García et al., 2014). As a result, there appeared some research in recent years devoted to the study of the response models including the effect of mowing (Xu et al., 2013).

Functional traits that are more sensitive to disturbances can serve as effective indicators for functional degradation of ecosystem, such as grassland community succession and loss of biodiversity (Díaz et al., 2007). Leaves are major functional organs of plants and have more stable strategies of self-protection (McIntire and Hik, 2002; Cruz et al., 2010). For example, L. chinensis, which grows in the meadow steppe of China, shows an increase in leaf-area in response to long-term high grazing pressure (Zheng et al., 2010), which improves the plant's relative photosynthesis capabilities (Badger, 2013). Furthermore, plant organs that grow in aboveground are typically more sensitive to defoliation than those that are below ground (Guo et al., 2012). Root traits have a slower response or are stable in response to changes in the soil microenvironment (Milchunas and Vandever, 2013). Moreover, in grazed grasslands that represent an "adverse habitat", plants adopt ecological strategies such as tradeoffs and changes in allometry to optimize their functions and complete their growth cycles (Cingolani et al., 2005; Niu et al., 2009; Acosta-Gallo et al., 2011).

Although some ecological studies have reported on the effects of mowing on plant traits (Schrama et al., 2013), the characteristic responses and tradeoffs as a result of mowing remain unclear. Several recent studies have focused on the function of mowing as a replacement to grazing by domestic animals (Benot et al., 2013), but none as a land management practice. Studies have shown that clipping reduces the root to shoot ratio and increases the root length in many plant species (Bahn et al., 2006; Thorne and Frank, 2009), yet mowing has no significant effect on root respiration (Thorne and Frank, 2009). Apparently, the effects of mowing on plant traits appear somewhat inconsistent. Functional tradeoff is an important adaptive strategy of plants growing in heterogeneous environments. Little is known about the allometry in leaf and stem traits of L. chinensis plants following mowing at various intensities in semi-arid grasslands. Therefore, the objective of this study was to investigate how L. chinensis responds to different mowing regimes. A long-term experiment was conducted with different mowing intensities to evaluate the effects of mowing on the functional traits of $L$. chinensis. The experiment is intended to address the following three questions: (1) How plastic are the functional traits of L. chinensis as a result of long-term mowing at various intensities? (2) Do these functional traits show the same or different degrees of plasticity in response to mowing? (3) What are the allometric relationships between the functional traits of $L$. chinensis following mowing disturbances?

\section{Materials and methods}

\subsection{Study area}

The study area is located at the Inner Mongolia Grassland Ecosystem Research Station $\left(43^{\circ} 38^{\prime} \mathrm{N}\right.$, $116^{\circ} 42^{\prime} \mathrm{E}$; $1,200 \mathrm{~m}$ asl) of the Chinese Academy of Sciences, in the Xilin River catchment of China. The Xilin River catchment has a semi-arid continental climate that is characterized by mean annual precipitation of $236 \mathrm{~mm}$ (1998-2012), and annual mean temperature of $3.2^{\circ} \mathrm{C}$. There is a high variability in precipitation between years, and the coefficient of variation of precipitation is $22 \%$. The changes in precipitation coincide with the changes in temperatures in June, July and 
August. The perennial plants grow from April/May to September/October, approximately $150 \mathrm{~d}$ (Li et al., 2015a). L. chinensis is a perennial rhizome grass that dominates in these steppe communities. The major soil types of this region are calcic chestnut and calcic chernozem (Bösing et al., 2014).

\subsection{Experimental design and sampling}

The experimental site was established in 1998 and contains grassland subjected to a long-term continuous mowing exclusion (unmown), and three intensities of mowing in a randomized block design (Baoyin et al., 2014). The experiment is located on a flatland area on the side of a 24-hm² permanent enclosure, where livestock grazing was prohibited. Three replicates of each of four mowing treatments (i.e. mowing frequencies) were randomly assigned to 12 permanent plots that were $10 \mathrm{~m} \times 10 \mathrm{~m}$ in size. The four treatments were: (1) CK, no clipping; (2) C1/2, clipping once every two years; (3) C1/1, clipping once a year; and (4) C2/1, clipping twice a year (Baoyin et al., 2014). At the time of harvest, a small hand-push lawn mower was used to cut the grass to a $6-\mathrm{cm}$ stubble height over the entire plot and the cut plant material was removed. The mowing was conducted each year on 16 August (or 1-3 d later depending on the weather) for the $\mathrm{C} 1 / 2$ and $\mathrm{C} 1 / 1$ treatments and on 15 June and 15 September for the C2/1 treatment.

Five $1 \mathrm{~m} \times 1 \mathrm{~m}$ quadrats were randomly selected in each of the 12 plots for field sampling. These quadrats were harvested on 15-20 August 2013, which corresponded with flowering of $L$. chinensis and peak-standing biomass. Three L. chinensis individuals were randomly selected in each of the quadrats. The aboveground portion of the plant was clipped to measure aboveground phenotypic traits. In total, 180 plants from 60 quadrats were measured.

Leaf length, leaf number, stem length, stem width and plant height were measured with an electronic digital caliper. Additionally, leaves were scanned using a digital scanner to determine leaf area using Adobe Photoshop CS5. After phenotypes were measured, leaves and stems were packaged in separate paper bags, and all of the plant samples were oven-dried at $65^{\circ} \mathrm{C}$ for at least $48 \mathrm{~h}$. Subsequently, the mass of the samples was measured to calculate their biomass.

\subsection{Data analysis}

Leaf length, width and area were measured and the mean of all leaves represented the individual leaf traits of the plant. The mean of the functional traits was calculated from measurements taken from three L. chinensis individuals in one quadrat and used for statistical analysis.

The relationship between plant traits and mowing intensity was evaluated using one-way ANOVA, followed by Duncan's Multiple Range Test procedures. Variation was analyzed by using a plasticity index (PI; Moreno and Bertiller, 2015):

$$
P I=\left(F_{n}-F_{m}\right) / F_{n} \text {. }
$$

Where $F_{n}$ is the functional trait of plants in habitats without mowing, and $F_{m}$ is the functional trait of plants subjected to different mowing intensities.

We analyzed allometric relationships using the classical allometry model (Warton et al., 2012):

$$
Y=a X^{b} \text {. }
$$

Where $a$ is the allometric coefficient and $b$ the allometric exponent. An exponent that is significantly different from 1.0 indicates an allometric (non-isometric) relationship. We used standardized major axis (SMA) analysis based on findings that model II regression (e.g. SMA) from other researchers (Niklas and Cobb, 2006), and SMA analysis is more appropriate than traditional least squares for fitting allometric data and estimating parameters. We tested whether the slope of each population was significantly different from 1.00. All of the SMA analyses were conducted using the Standardized Major Axis Tests and Routines (SMATR) software package (Falster et al., 2006).

Structural equation modeling (SEM) was performed to analyze hypotheses that may explain the pathways responsible for the indirect effects of mowing on L. chinensis biomass accumulation (Byrne, 2013). SEMs were developed based on hypothesized relationships between variables and testing of preliminary models. Depending on the model and variable, it was necessary to alter the relationship between a measured L. chinensis functional trait and the rest of the model. We 
compared the utility of each functional trait index within the SEM based on a number of measures, including the power of the particular model for explaining the variation in L. chinensis biomass accumulation $\left(R^{2}\right)$, measures of model significance and fit $\left(\chi^{2}\right)$, and the significance of the functional trait variables within the model (significance of regression weights) (Li et al., 2015b). SEM analysis was performed using IBM SPSS AMOS 18.0 software packages.

Correlations among plant traits of L. chinensis were analyzed by using Pearson's correlation coefficient. All analyses testing the significant differences between means were conducted using IBM SPSS 19.0 software (SPSS Inc., Chicago, IL, USA), and results were considered significant when $P<0.05$ level.

\section{Results}

\subsection{Plasticity of plant traits in response to mowing}

With the increase of mowing intensity, the leaf and stem parameters (leaf length, leaf width, leaf area, stem length and stem diameter) gradually decreased in size $(P<0.05)$. The plant height also decreased with the increase of mowing intensity $(P<0.05$; Table 1$)$. When we ranked the functional traits by their plasticity indices, we observed differences in some traits (e.g. stem biomass, aboveground biomass, leaf area and plant height) and a lack of responses in other traits (e.g. leaf number, leaf mass, leaf width and stem diameter) in response to different mowing intensities (Fig. 1a). In the $\mathrm{C} 1 / 2, \mathrm{C} 1 / 1$ and $\mathrm{C} 2 / 1$ treatments, the plasticity indices of the functional traits were positively correlated with increases of mowing intensity $(P<0.01$; Fig. 1b).

Table 1 Leaf and stem morphological traits of Leymus chinensis (Trin.) Tzvel. in response to long-term mowing at various intensities

\begin{tabular}{|c|c|c|c|c|c|}
\hline \multirow{2}{*}{$\begin{array}{l}\text { Plant } \\
\text { traits }\end{array}$} & \multicolumn{4}{|c|}{ Mowing intensity treatments } & \multirow[b]{2}{*}{$F$ value } \\
\hline & $\mathrm{CK}$ & $\mathrm{C} 1 / 2$ & $\mathrm{C} 1 / 1$ & $\mathrm{C} 2 / 1$ & \\
\hline LN & $5.53 \pm 0.64^{\mathrm{a}}$ & $5.67 \pm 0.72^{\mathrm{a}}$ & $5.73 \pm 0.59^{\mathrm{a}}$ & $4.53 \pm 0.52^{\mathrm{b}}$ & $12.19^{* *}$ \\
\hline $\mathrm{LL}(\mathrm{cm})$ & $26.35 \pm 1.88^{\mathrm{a}}$ & $23.57 \pm 2.21^{\mathrm{b}}$ & $19.75 \pm 1.86^{\mathrm{c}}$ & $14.94 \pm 1.29^{\mathrm{d}}$ & $108.27^{* *}$ \\
\hline LW (mm) & $8.90 \pm 0.53^{\mathrm{a}}$ & $7.91 \pm 0.80^{\mathrm{b}}$ & $6.98 \pm 0.46^{c}$ & $6.65 \pm 0.62^{\mathrm{c}}$ & $40.77^{* *}$ \\
\hline $\mathrm{LA}\left(\mathrm{cm}^{2}\right)$ & $15.39 \pm 1.71^{\mathrm{a}}$ & $12.30 \pm 2.24^{\mathrm{b}}$ & $9.04 \pm 1.14^{\mathrm{c}}$ & $6.51 \pm 0.85^{\mathrm{d}}$ & $89.68^{* *}$ \\
\hline $\mathrm{SL}(\mathrm{mm})$ & $37.69 \pm 4.36^{\mathrm{a}}$ & $28.63 \pm 2.89^{b}$ & $25.21 \pm 2.47^{\mathrm{c}}$ & $15.59 \pm 2.13^{\mathrm{d}}$ & $131.58^{* *}$ \\
\hline $\mathrm{SD}(\mathrm{cm})$ & $2.02 \pm 0.17^{\mathrm{a}}$ & $1.89 \pm 0.13^{\mathrm{b}}$ & $1.72 \pm 0.14^{\mathrm{b}}$ & $1.88 \pm 0.16^{\mathrm{c}}$ & $10.30^{* *}$ \\
\hline $\mathrm{PH}(\mathrm{cm})$ & $63.11 \pm 4.37^{\mathrm{a}}$ & $52.33 \pm 3.78^{\mathrm{b}}$ & $45.03 \pm 2.69^{c}$ & $32.15 \pm 2.97^{\mathrm{d}}$ & $204.94^{* *}$ \\
\hline
\end{tabular}

Note: Mowing intensities are as follows: CK, no clipping; C1/2, clippling once every two years; C1/1, clipping once a year; C2/1, clipping twice a year. Plants trait measurements include: LN, leaf number; LL, leaf length; LW, leaf width; LA, leaf area; SL, stem length; SD, stem diameter; PH, plant height. Superscript letters indicate the statistical significance between different variables, and variables with the same letter are not significantly different $(P>0.05)$ among the four mowing intensity treatments. ${ }^{* *}$ indicates the significance at $P<0.01$ level.

\subsection{Changes in allometry among leaf traits in response to mowing}

Except for leaf number and leaf width $(P>0.05)$, all other leaf functional traits were positively correlated with each other $(P<0.01$; Table 2$)$. We conducted a SMA analysis and found that all leaf traits had significant allometric scaling relationships with other leaf traits $(P<0.01)$, except for leaf number and leaf width $(P>0.05$; Table 2$)$. Leaf length to width ratio was positively correlated with all leaf traits, which was fitted by the equation of exponential rise to maximum or linear relationships $(P<0.05$; Fig. 2). The slopes of the allometric equations for leaf mass with leaf width and leaf area show significant heterogeneity across the four mowing intensity treatments, and these allometric ratios were significantly influenced by mowing $(P<0.05$, Table 2$)$. We did not observe a significant difference in the effect of mowing on the slopes of the bivariate relationships of other groups $(P>0.05)$. However, we observed a significant shift along the common slope of seven of the bivariate relationships $(P<0.05)$, except for the bivariate relationship of leaf mass with leaf length (Table 2). Lastly, there were significant shifts along the common slope among leaf traits across the mowing intensity treatments (Table 2). 

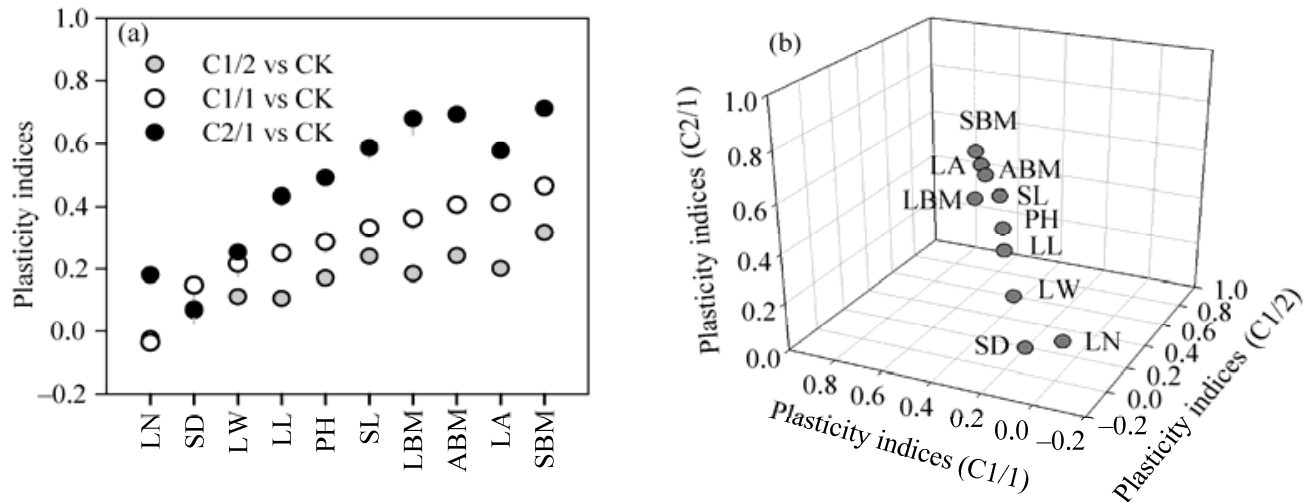

Fig. 1 The plasticity indices (a) and their similarity (b) of various functional traits in Leymus chinensis (Trin.) Tzvel. subjected to different mowing intensity treatments, and compared to the unclipped treatment. CK, no clipping; $\mathrm{C} 1 / 2$, clipping once every two years; $\mathrm{C} 1 / 1$, clipping once a year; $\mathrm{C} 2 / 1$, clipping twice a year. SBM, stem biomass; LBM, leaf biomass; ABM, aboveground biomass. Other abbreviations are described in Table 1.

Table 2 The relationship of leaf traits of Leymus chinensis (Trin.) Tzvel. at the four mowing intensities using standardized major axis (SMA) regression slopes

\begin{tabular}{|c|c|c|c|c|c|c|c|c|}
\hline \multirow{2}{*}{ Y vs $\mathrm{X}$} & \multicolumn{2}{|c|}{ Combined } & \multicolumn{4}{|c|}{ Allometric slopes across four mowing intensity treatment } & \multirow{2}{*}{$\begin{array}{c}\text { Common } \\
\text { slope }\end{array}$} & \multirow{2}{*}{ Shift } \\
\hline & $R^{2}$ & Slope & $\mathrm{CK}$ & $\mathrm{C} 1 / 2$ & $\mathrm{C} 1 / 1$ & $\mathrm{C} 2 / 1$ & & \\
\hline LL vs LN & $0.19^{* *}$ & $1.58^{* *}$ & $0.64^{\mathrm{ns}}$ & $-0.79^{\text {ns }}$ & $-0.91^{\mathrm{ns}}$ & $-0.75^{\mathrm{ns}}$ & $-0.76^{\mathrm{ns}}$ & Yes \\
\hline LW vs LN & $0.06^{\mathrm{ns}}$ & $0.95^{\mathrm{ns}}$ & $\begin{array}{c}0.53^{* *} \\
(0.34,0.81)\end{array}$ & $-0.82^{\text {ns }}$ & $-0.65^{\text {ns }}$ & $-0.80^{\mathrm{ns}}$ & $0.67^{\mathrm{ns}}$ & Yes \\
\hline LA vs LN & $0.15^{* *}$ & $2.41^{* *}$ & $0.98^{\mathrm{ns}}$ & $-1.55^{\mathrm{ns}}$ & $-1.28^{\mathrm{ns}}$ & $-1.13^{\text {ns }}$ & $-1.17^{\mathrm{ns}}$ & Yes \\
\hline LBM vs LN & $0.38^{* *}$ & $3.14^{* *}$ & $\begin{array}{c}1.69^{* *} \\
(1.18,2.42)\end{array}$ & $1.43^{\mathrm{ns}}$ & $\begin{array}{c}1.83^{*} \\
(1.05,3.17)\end{array}$ & $-1.12^{\mathrm{ns}}$ & $1.55^{\mathrm{ns}}$ & Yes \\
\hline LW vs LL & $0.65^{* *}$ & $0.60^{* *}$ & $0.82^{\mathrm{ns}}$ & $1.05^{\mathrm{ns}}$ & $0.71^{\mathrm{ns}}$ & $1.08^{\mathrm{ns}}$ & $0.94^{\mathrm{ns}}$ & Yes \\
\hline LA vs LL & $0.95^{* *}$ & $1.53^{* *}$ & $\begin{array}{c}1.53^{* *} \\
(1.14,2.04)\end{array}$ & $\begin{array}{c}1.97^{* *} \\
(1.66,2.33)\end{array}$ & $\begin{array}{c}1.40^{*} \\
(1.07,1.87)\end{array}$ & $\begin{array}{c}1.51^{*} \\
(1.00,2.28)\end{array}$ & $1.70^{\mathrm{ns}}$ & Yes \\
\hline LBM vs LL & $0.87^{* *}$ & $1.99^{* *}$ & $\begin{array}{c}2.64^{* *} \\
(1.70,4.09)\end{array}$ & $\begin{array}{c}1.82^{* *} \\
(1.21,2.74)\end{array}$ & $\begin{array}{c}2.01^{* *} \\
(1.25,3.23)\end{array}$ & $1.50^{\mathrm{ns}}$ & $1.99^{\mathrm{ns}}$ & No \\
\hline LA vs LW & $0.85^{* *}$ & $2.54^{* *}$ & $\begin{array}{c}1.87^{* *} \\
(1.32,2.66)\end{array}$ & $\begin{array}{c}1.88^{* *} \\
(1.60,2.21)\end{array}$ & $\begin{array}{c}1.99^{* *} \\
(1.35,2.93)\end{array}$ & $1.40^{\mathrm{ns}}$ & $1.83^{\mathrm{ns}}$ & Yes \\
\hline LBM vs LW & $0.67^{* *}$ & $3.30^{* *}$ & $\begin{array}{c}3.23^{* *} \\
(2.22,4.68)\end{array}$ & $\begin{array}{c}1.74^{* *} \\
(1.21,2.50)\end{array}$ & $\begin{array}{c}2.83^{* *} \\
(1.85,4.32)\end{array}$ & $1.40^{\mathrm{ns}}$ & $2.21^{*}$ & / \\
\hline LBM vs LA & $0.88^{* *}$ & $1.30^{* *}$ & $\begin{array}{c}1.73^{* *} \\
(1.26,2.37)\end{array}$ & $0.93^{\mathrm{ns}}$ & $1.42^{\mathrm{ns}}$ & $1.00^{\mathrm{ns}}$ & $1.28^{*}$ & l \\
\hline
\end{tabular}

Note: Slopes of SMA slopes are shown for the four mowing intensity treatments. The $95 \%$ confidence intervals (CIs) of these slopes are indicated in parenthesis in the table when the allometric slopes are significantly different from 1.00 (i.e. $P<0.05$ ). Some conditions did not show significant differences between the four groups (i.e. $P>0.05$ ), and for those cases, common slopes and $95 \%$ CIs are not shown. Significant shifts along a common slope are indicated (Yes or No). Same abbreviations are used as Table 1 and Fig. $1 .{ }^{*}$ and ${ }^{* *}$ indicate the significance at $P<0.05$ and $P<0.01$ levels, respectively; ${ }^{\text {ns }}$ indicates no significance.

\subsection{Effect of mowing on allometry of stem traits}

We tested the effect of mowing on stem functional traits, including stem length, stem diameter and stem biomass. These stem functional traits were positively correlated with each other $(P<0.01$; Table 3), and the three stem traits had allometric scaling slopes that were significantly different from $1.0(P<0.01$; Table 3). Additionally, because it was affected by the allometric scaling of stem traits, the stem length to diameter ratio was positively correlated with stem length and stem biomass when the relationship was fitted by equations of linear $(P<0.01)$ and exponential rise to maximum $(P<0.01$; Fig. 3$)$. Although there was a significant effect of mowing on the difference in the slopes of the bivariate relationships of the three groups $(P>0.05)$, there was a significant shift along the common slope of three of the bivariate relationships (Table 3). Also, there were significant shifts along the common slope of stem traits with plant height across the mowing intensities (Table 4). 

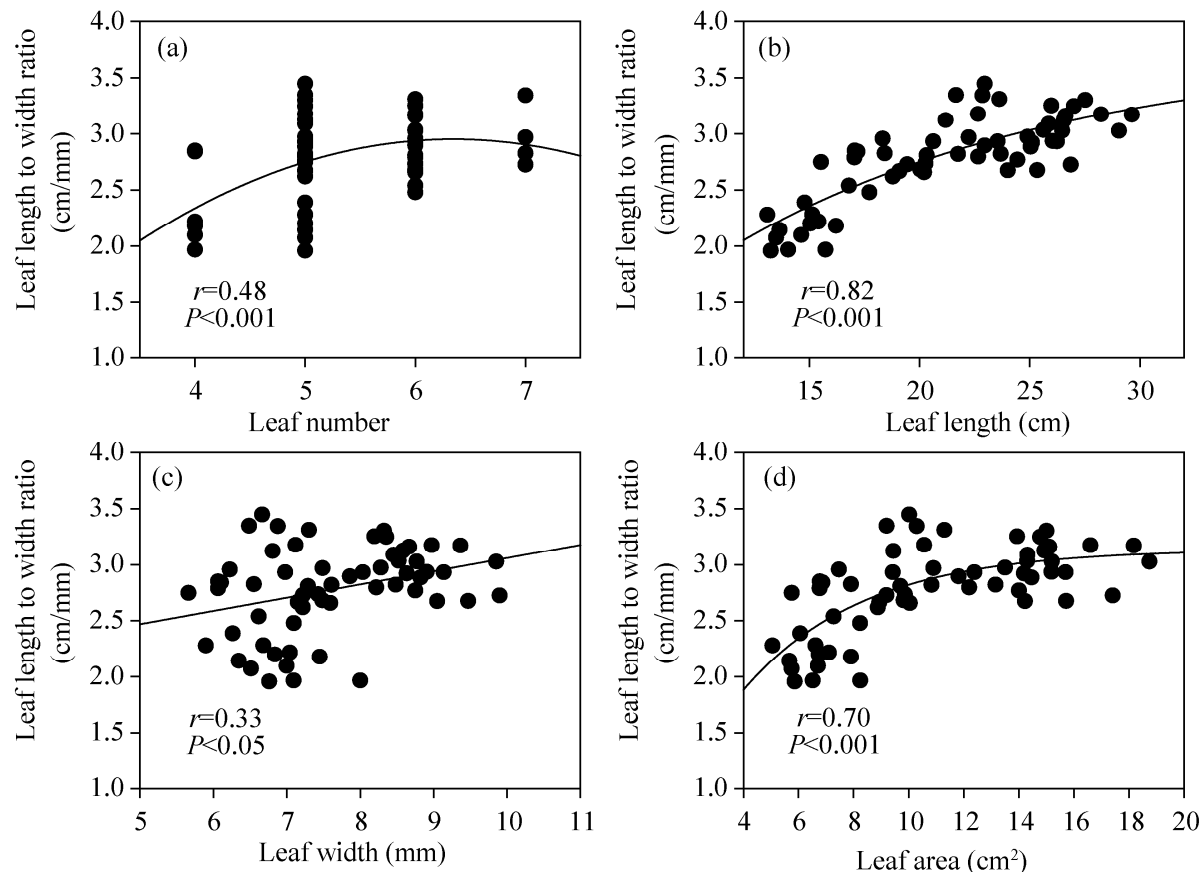

Fig. 2 Relationship of leaf length to width ratios in Leymus chinensis (Trin.) Tzvel. individuals to leaf morphological traits under the four mowing intensity treatments. (a), no clipping; (b), clipping once every two years; (c), clipping once a year; (d), clipping twice a year.

Table 3 The relationship of stem traits in Leymus chinensis (Trin.) Tzvel. under four mowing intensity treatments analyzed by standardized major axis (SMA) regression slopes

\begin{tabular}{|c|c|c|c|c|c|c|c|c|}
\hline \multirow{2}{*}{ Y vs $\mathrm{X}$} & \multicolumn{2}{|c|}{ Combined } & \multicolumn{4}{|c|}{ Allometric slopes across four mowing intensities } & \multirow{2}{*}{$\begin{array}{c}\text { Common } \\
\text { slope }\end{array}$} & \multirow{2}{*}{ Shift } \\
\hline & $R^{2}$ & Slope & CK & $\mathrm{C} 1 / 2$ & $\mathrm{C} 1 / 1$ & $\mathrm{C} 2 / 1$ & & \\
\hline SL vs SD & $0.13^{* *}$ & $0.28^{* *}$ & $1.45^{\mathrm{ns}}$ & $1.45^{\mathrm{ns}}$ & $1.18^{\mathrm{ns}}$ & $1.64^{\mathrm{ns}}$ & $1.44^{\mathrm{ns}}$ & Yes \\
\hline SBM vs SD & $0.93^{* *}$ & $1.48^{* *}$ & $\begin{array}{c}2.83^{* *} \\
(1.85,4.33)\end{array}$ & $\begin{array}{c}3.17^{* *} \\
(2.02,4.96)\end{array}$ & $\begin{array}{c}2.31^{* *} \\
(1.51,3.53)\end{array}$ & $\begin{array}{c}2.81^{* *} \\
(1.96,4.02)\end{array}$ & $2.75^{\mathrm{ns}}$ & Yes \\
\hline SBM vs SL & $0.24^{* *}$ & $5.25^{* *}$ & $\begin{array}{c}1.96^{* *} \\
(1.42,2.71)\end{array}$ & $\begin{array}{c}2.18^{* *} \\
(1.39,3.42)\end{array}$ & $\begin{array}{c}1.96^{* *} \\
(1.28,2.99)\end{array}$ & $\begin{array}{c}1.71^{* *} \\
(1.32,2.23)\end{array}$ & $1.87^{\mathrm{ns}}$ & Yes \\
\hline
\end{tabular}

Note: The abbreviations and symbols are as described in Table 1, Table 2 and Fig. 1.
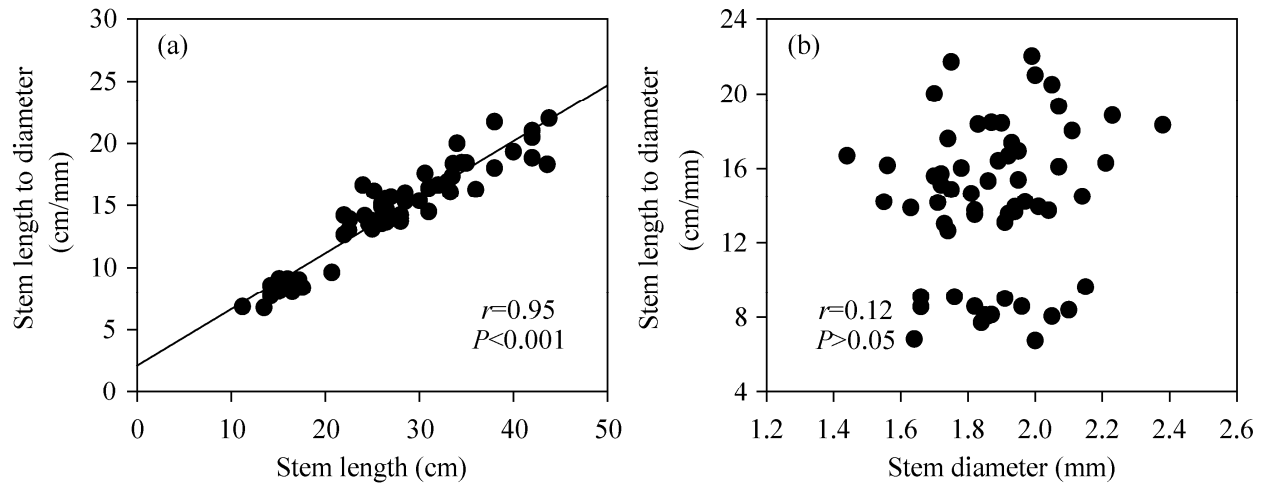

Fig. 3 Relationship of stem length to diameter ratios in Leymus chinensis (Trin.) Tzvel. individuals to stem morphological traits under the four mowing intensity treatments

\subsection{SEM for plant biomass}

Leaf and stem biomass significantly decreased $(P<0.05)$ with increasing mowing intensity (Fig. 4). We found a significant positive correlation of biomass accumulation in individual plants with all of the leaf and stem functional traits $(P<0.05$; Tables $2-4)$. Mowing indirectly changed biomass accumulation, through a 'bottom-up' effect of leaf and stem traits. Leaf length was the most 
Table 4 Comparison of plant heights with leaf and stem traits of Leymus chinensis (Trin.) Tzvel. subjected to different mowing intensities using SMA regression analysis

\begin{tabular}{|c|c|c|c|c|c|c|c|c|}
\hline \multirow{2}{*}{ Item } & \multicolumn{2}{|c|}{ Combined } & \multicolumn{4}{|c|}{ Allometric slopes across four mowing intensities } & \multirow{2}{*}{$\begin{array}{c}\text { Common } \\
\text { slope }\end{array}$} & \multirow{2}{*}{ Shift } \\
\hline & $R^{2}$ & Slope & CK & $\mathrm{C} 1 / 2$ & $\mathrm{C} 1 / 1$ & $\mathrm{C} 2 / 1$ & & \\
\hline LN & $0.25^{* *}$ & $0.57^{* *}$ & $0.63^{\text {ns }}$ & $-0.60^{\text {ns }}$ & $\begin{array}{c}0.56^{*} \\
(0.32,0.99)\end{array}$ & $-0.81^{\mathrm{ns}}$ & $0.65^{\mathrm{ns}}$ & Yes \\
\hline LL & $0.91^{* *}$ & $0.89^{*}$ & $0.97^{\mathrm{ns}}$ & $0.76^{\mathrm{ns}}$ & $\begin{array}{c}0.62^{*} \\
(0.40,0.96)\end{array}$ & $1.09^{\text {ns }}$ & $0.85^{\mathrm{ns}}$ & Yes \\
\hline LW & $0.68^{* *}$ & $0.54^{* *}$ & $1.19^{\mathrm{ns}}$ & $\begin{array}{c}0.72^{*} \\
(0.53,0.99)\end{array}$ & $0.88^{\text {ns }}$ & $1.01^{\mathrm{ns}}$ & $0.87^{\mathrm{ns}}$ & Yes \\
\hline LA & $0.91^{* *}$ & $1.37^{* *}$ & $\begin{array}{c}0.64^{*} \\
(0.42,0.96)\end{array}$ & $\begin{array}{c}0.38^{* *} \\
(0.27,0.56)\end{array}$ & $\begin{array}{c}0.44^{* *} \\
(0.29,0.67)\end{array}$ & $0.72^{\mathrm{ns}}$ & $0.52^{\mathrm{ns}}$ & Yes \\
\hline LBM & $0.89^{* *}$ & $1.78^{* *}$ & $\begin{array}{c}0.37^{* *} \\
(0.24,0.58)\end{array}$ & $\begin{array}{c}0.42^{* *} \\
(0.29,0.60)\end{array}$ & $\begin{array}{c}0.31^{* *} \\
(0.18,0.52)\end{array}$ & $0.73^{\text {ns }}$ & $0.42^{\mathrm{ns}}$ & Yes \\
\hline SD & $0.95^{* *}$ & $1.31^{* *}$ & $0.87^{\mathrm{ns}}$ & $1.09^{\mathrm{ns}}$ & $0.72^{\mathrm{ns}}$ & $1.12^{\mathrm{ns}}$ & $0.93^{\text {ns }}$ & Yes \\
\hline SL & $0.17^{* *}$ & $0.37^{* *}$ & $\begin{array}{c}0.60^{* *} \\
(0.45,0.80)\end{array}$ & $0.75^{\text {ns }}$ & $\begin{array}{c}0.61^{*} \\
(0.40,0.92)\end{array}$ & $\begin{array}{c}0.68^{*} \\
(0.50,0.93)\end{array}$ & $0.65^{\text {ns }}$ & Yes \\
\hline SBM & $0.91^{* *}$ & $1.94^{* *}$ & $\begin{array}{c}0.31^{* *} \\
(0.21,0.45)\end{array}$ & $\begin{array}{c}0.34^{* *} \\
(0.23,0.51)\end{array}$ & $\begin{array}{c}0.31^{* *} \\
(0.20,0.49)\end{array}$ & $\begin{array}{c}0.40^{* *} \\
(0.26,0.61)\end{array}$ & $0.34^{\mathrm{ns}}$ & Yes \\
\hline
\end{tabular}

Note: The abbreviations and symbols are described in Table 1, Table 2 and Fig. 1.

important pathway determining leaf mass decline $(P<0.05)$, while the leaf number and width did not correlate significantly with leaf mass $(P>0.05$; Fig. 4$)$. The primary pathway that determined stem mass was stem length $(P<0.05)$, but not stem diameter (Fig. 4). In addition, specific leaf area was significantly increased in $\mathrm{C} 2 / 1$ treatment compared to the other three mowing regimes $(P<0.05$; Fig. 4). Moreover, correlation analysis showed that there were significant negative correlations between specific leaf area and plant traits $(P<0.05$; Fig. 5).

(a)

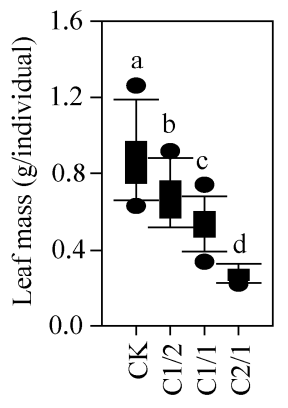

(b)

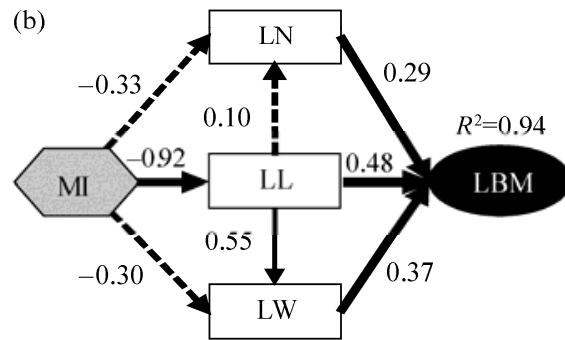

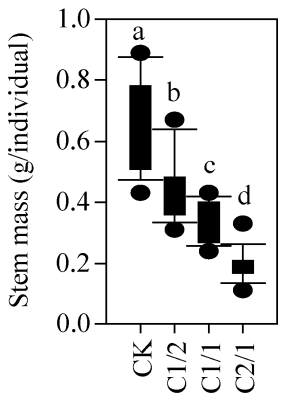
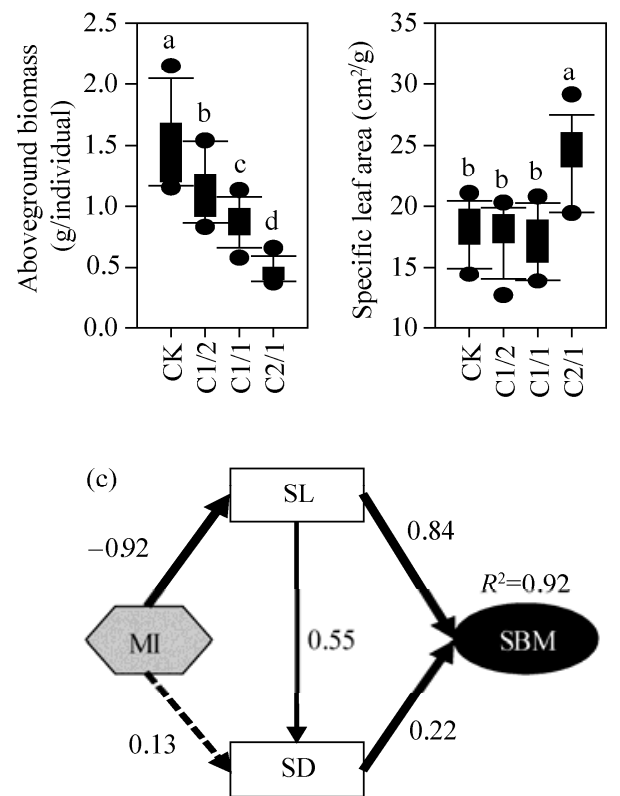

Fig. 4 Effects of mowing intensities on aboveground biomass of Leymus chinensis (Trin.) Tzvel. Values with the same letter are not significantly different $(P>0.05)$ among the four mowing intensity treatments (a). The effect of mowing on processes of leaf and stem biomass decline via plant functional traits pathways (b and c). Values associated with arrows represent standardized path coefficients. Solid arrows represent significant paths $(P<0.05)$ in a fitted structural equation model (SEM), depicting impact of variables on leaf and stem mass accumulation per individual. Results of model fitting: LBM, leaf biomass $\left(\chi^{2}=2.860, P=0.239\right)$; SBM, stem biomass $\left(\chi^{2}=0.015\right.$, $P=0.901)$. Dashed arrows represent the directions and effects that were not significant $(P>0.05) . R^{2}$ values associated with response variables indicate the proportion of variation explained by relationships with other variables. MI, mowing intensities. Other abbreviations are described in Table 1 and Fig. 1. 

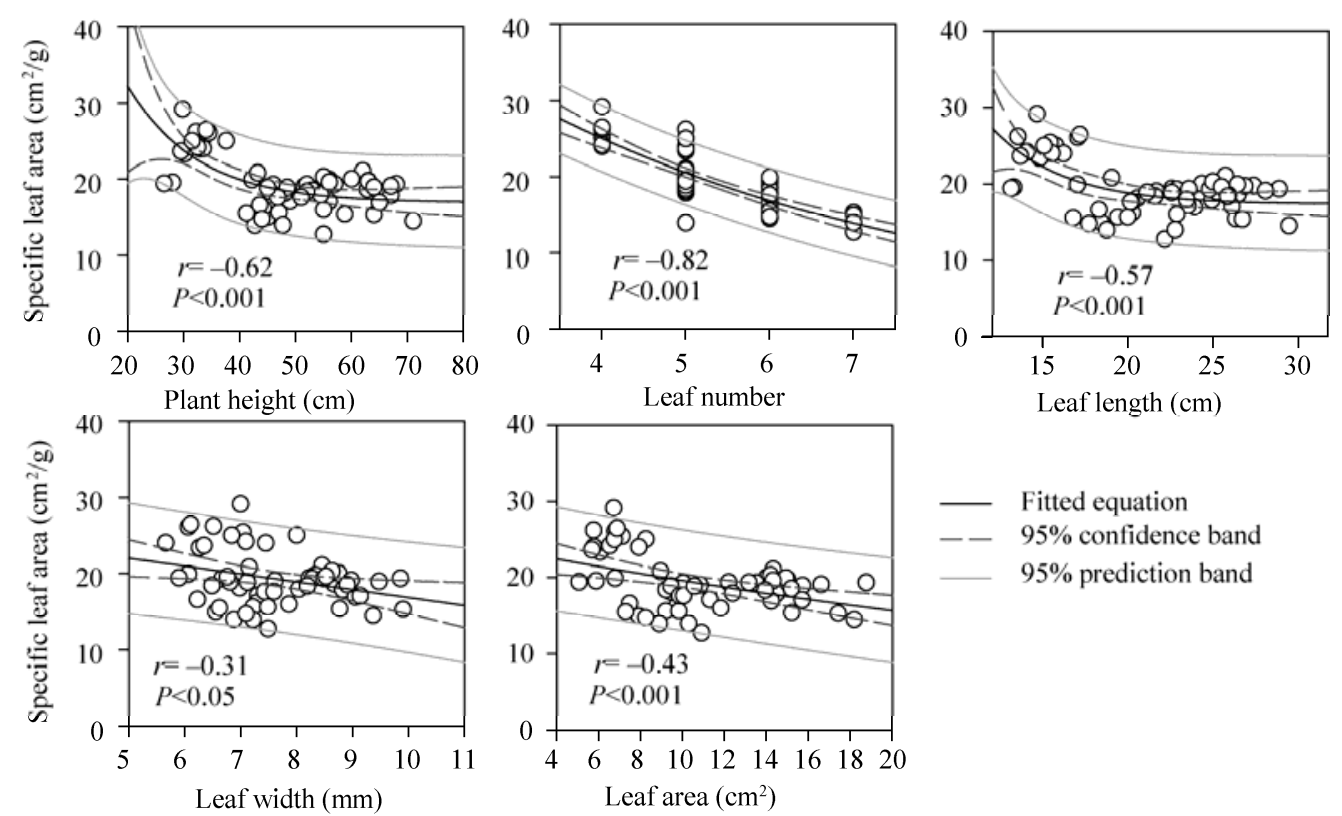

Fig. 5 Correlations between specific leaf area with plant height and leaf morphological traits of Leymus chinensis (Trin.) Tzvel. under the four mowing intensity treatments

\section{Discussion}

Plants use morphological plasticity to adapt to heterogeneous habitats and gain access to resources effectively (Davidson et al., 2011). Previous studies have reported that plants become smaller when subjected to continuous herbivore grazing pressure (Díaz et al., 2007). Theoretically, the removal of photosynthetic shoot tissue by mowing can give insights into the role of defoliation, which mainly occurs as a result of grazing and is a key mechanism by which large herbivores affect grassland ecosystem functioning (Chen et al., 2014). Increasingly, we found similar results indicating there are some similarities in the changes in plant functional traits between mowing and grazing. The ecological advantage of reduced size in leaves and stems of plants may be related to persistent pressure; for example, a previous study had found that phenotypic plasticity served as an important mechanism to avoid disturbance in mown habitats (Baoyin et al., 2014). By conducting a meta-analysis of 197 papers on the response of plants to grazing, Díaz et al. (2007) showed that plant traits became physically smaller under increasing grazing pressure. Hence plants adapt to mowing or grazing disturbance by means of phenotypic plasticity, which serve as a rapid reaction mechanism.

Plant functional traits that are linked to ecosystem functions, such as productivity and biodiversity, are adapted to mowing (Lavorel, 2013). We found that leaf number, leaf length, leaf width, leaf area, stem length, stem diameter and plant height were impacted by long-term mowing, with a significant decrease in these traits in clipped plants compared to the un-clipped plants. However, not all grassland plant species have the same phenotypic plasticity reaction (Díaz et al., 2007). For example, distinctions could be made between "mowing-susceptible" and "mowing-resistant" plants in their responses to long-term stresses in heterogeneous habitats, and L. chinensis is the dominant species in Inner Mongolian grassland that is mowing-susceptible ( $\mathrm{Li}$ et al., 2015b). Therefore, the reduction in physical characteristics of L. chinensis will likely have a substantial effect on the structure and functioning of grassland ecosystems. Thus, the mowing-susceptible nature of $L$. chinesis may lead to a cascade of reactions in the grassland, beginning with functional traits, then progressing to other individuals, species, populations and ecosystems (Lavorel et al., 2011; Makkonen et al., 2012).

Our results showed that mowing also indirectly changed biomass accumulation, through a "bottom-up" effect of leaf and stem traits. In general, grassland productivity, which primarily 
relies on plant biomass, is an important function of a grassland ecosystem ( $\mathrm{Li}$ et al., 2015b). Under the pressure of human activity and climate change, the decrease of grassland productivity could have a substantial impact on the global ecosystem (Li et al., 2014). To date, several studies have reported on how productivity declines from the perspective of biodiversity loss (Middleton et al., 2006). However, our results show that long-term mowing reduces the plant's biomass, which contributes to grassland productivity loss. Furthermore, aboveground biomass of plants declined with mowing, because the clipped plants had reduced physical size and smaller organs. Thus, disturbance-induced phenotypic plasticity of grassland plants is potentially a key process related to the decline of grassland productivity.

In this study, we observed differences in allometries between different traits of L. chinensis subjected to a range of mowing intensities. Our results are consistent with previous studies; for example, Niu et al. (2009) reported the allometry of reproductive biomass in response to grazing, and that plants alter allometric ratios to efficiently use resources in metastable habitats (Niu et al., 2009). Previous studies have reported that allometry of different plants' functional traits is a common phenomenon in many ecosystems, where they serve as effective strategies for adaptation in heterogeneous habitats, both long-term and short-term (Van Bodegom et al., 2012; Laing et al., 2014). Therefore, our results of the allometry between leaf and stem to mowing disturbance may be a useful strategy in disturbance avoidance.

Our results showed that some traits, such as stem traits and plant height, were sensitive to mowing. Yet other traits, such as leaf number, leaf width and stem diameter, were not sensitive traits to mowing. Leaves are the major functional organ in plants, and play many important roles. Zheng et al. (2010) reported that leaf number of L. chinensis increased in response to long-term grazing, while the size of leaves decreased across six grassland communities in the Xilin River Basin of Inner Mongolia. In contrast, we found that leaf number decreased when plants were clipped compared to that of un-clipped. The disparity between our results and those of Zheng et al. (2010)'s could be explained as follows. First, the plant species were different in the two studies, and there may be species-specific responses to mowing in leaf traits. Second, utilization history affected the allometry relationship, with long-term mowing and grazing altering the ability to increase leaf number under the pressure of grazing and mowing. Lastly, we collected samples from plots, while Zheng et al. (2010) collected from transects. The tradeoff between leaf number and leaf size may, therefore, be contingent on species, grazing history, and/or ecological scale.

Moreover, we also found that leaf length/width, stem length/diameter and leaf mass per area (i.e. inverse specific leaf area) decreased in habitats subjected to mowing. These results suggest that they are strategies for a plant to limit photosynthesis with the reduced size of individual $L$. chinensis plants. This hypothesis is supported by a previous study, where these traits were related to plant photosynthesis. Laliberté and Tylianakis (2012) found that leaves became thinner in plants that had low leaf mass per area in disturbed environments. Therefore, the observed allometry in leaf and stem phenotypic and biomass traits in plants subjected to long-term mowing implies that $L$. chinensis may have adaptive photosynthesis strategies when subjected to mowing.

\section{Conclusions}

In conclusion, we found that the majority of leaf, stem and individual plant functional traits of $L$. chinensis in natural semi-arid grassland were significantly affected by mowing disturbances. Additionally, the plasticity indices were positively correlated with mowing intensity. Different functional traits appeared to respond asymmetrically to long-term mowing disturbances. In general, stem traits responded to mowing with higher plasticity than leaf traits. The sensitive traits and insensitive traits of $L$. chinensis were similar across all mowing intensities. Correlating mowing and the asymmetric responses of traits, we found significant allometric relationships among most $L$. chinensis functional traits. In addition, the sensitive traits of L. chinensis, such as leaf length and stem length, were the most important pathways determining the decline of aboveground biomass induced by long-term mowing. Therefore, we demonstrated that plant species (e.g. the dominant L. chinensis plants) in natural semi-arid grassland can develop an 
enhanced adaptive ability in response to long-term continuous mowing by means of changes in allometry between leaf and stem functional traits.

\section{Acknowledgements}

This study was financially supported by the National Basic Research Program of China (2014CB138806), the Natural Science Fund Project of Inner Mongolia (2015ZD02), the International Science and Technology Cooperation Program of China (2013DFR30760), the National Scientific and Technical Support Program of China (2012BAD12B02) and the Special Fund for Agro-scientific Research in the Public Interest (201303060). We thank the Inner Mongolia University and the Inner Mongolia Grassland Ecosystem Research Station of the Chinese Academy of Sciences for the implement of experiment. We especially thank Professor FAN Xiaobing from Inner Mongolia University of Technology for his constructive suggestions on this manuscript. We also thank the anonymous reviewers and editors for their valuable comments to greatly improve our manuscript.

\section{References}

Acosta-Gallo B, Casado M A, Montalvo J, et al. 2011. Allometric patterns of below-ground biomass in Mediterranean grasslands. Plant Biosystems-An International Journal Dealing with All Aspects of Plant Biology, 145(3): 584-595.

Badger M R. 2013. Role of plant leaf development in optimising photosynthetic efficiency, capacity, growth and yield. In: Gready J E, Dwyer S A, Evans J R. Applying Photosynthesis Research to Improvement of Food Crops. Canberra: Australian Centre for International Agricultural Research, 20.

Bahn M, Knapp M, Garajova Z, et al. 2006. Root respiration in temperate mountain grasslands differing in land use. Global Change Biology, 12(6): 995-1006.

Baoyin T, Li F Y, Bao Q H, et al. 2014. Effects of mowing regimes and climate variability on hay production of Leymus chinensis (Trin.) grassland in northern China. The Rangeland Journal, 36(6): 593-600.

Benot M L, Mony C, Lepš J, et al. 2013. Are clonal traits and their response to defoliation good predictors of grazing resistance? Botany, 91(2): 62-68.

Bösing B M, Susenbeth A, Hao J, et al. 2014. Effect of concentrate supplementation on herbage intake and live weight gain of sheep grazing a semi-arid grassland steppe of North-Eastern Asia in response to different grazing management systems and intensities. Livestock Science, 165: 157-166.

Byrne H, Conroy P J, Whisstock J C, et al. 2013. A tale of two specificities: bispecific antibodies for therapeutic and diagnostic applications. Trends in Biotechnology, 31(11): 621-632.

Chen S Y, Cai Y Y, Zhang L X, et al. 2014. Transcriptome analysis reveals common and distinct mechanisms for sheep grass (Leymus chinensis) responses to defoliation compared to mechanical wounding. PLoS ONE, 9(2): e89495.

Cingolani A M, Posse G, Collantes M B. 2005. Plant functional traits, herbivore selectivity and response to sheep grazing in Patagonian steppe grasslands. Journal of Applied Ecology, 42(1): 50-59.

Cruz P, De Quadros F L L, Theau J P, et al. 2010. Leaf traits as functional descriptors of the intensity of continuous grazing in native grasslands in the south of Brazil. Rangeland Ecology \& Management, 63(3): 350-358.

Davidson A M, Jennions M, Nicotra A B. 2011. Do invasive species show higher phenotypic plasticity than native species and, if so, is it adaptive? A meta-analysis. Ecology Letters, 14(4): 419-431.

Díaz S, Lavorel S, McIntyre S, et al. 2007. Plant trait responses to grazing-a global synthesis. Global Change Biology, 13(2): 313-341.

Falster D S, Warton D I, Wright I J. 2006. SMATR: Standardised major axis tests and routines, ver 2.0. [2015-12-20]. http://www.bio.mq.edu.au/ecology/SMATR/.

Guo Y J, Han L, Li G D, et al. 2012. The effects of defoliation on plant community, root biomass and nutrient allocation and soil chemical properties on semi-arid steppes in northern China. Journal of Arid Environments, 78: 128-134.

Han W W, Luo Y J, Du G Z. 2007. Effects of clipping on diversity and above-ground biomass associated with soil fertility on an alpine meadow in the eastern region of the Qinghai-Tibetan Plateau. New Zealand Journal of Agricultural Research, 50(3): 361-368.

He N P, Yu Q, Wu L, et al. 2008. Carbon and nitrogen store and storage potential as affected by land-use in a Leymus chinensis grassland of northern China. Soil Biology and Biochemistry, 40(12): 2952-2959.

Herrero-Jáuregui C, Schmitz M, Pineda F. 2014. Effects of different clipping intensities on above- and below-ground production in simulated herbaceous plant communities. Plant Biosystems, 150(3): 468-476.

Laing C G, Granath G, Belyea L R, et al. 2014. Tradeoffs and scaling of functional traits in Sphagnum as drivers of carbon cycling in peatlands. Oikos, 123(7): 817-828. 
Laliberté E, Tylianakis J M. 2012. Cascading effects of long-term land-use changes on plant traits and ecosystem functioning. Ecology, 93(1): 145-155.

Lavorel S, Grigulis K, Lamarque P, et al. 2011. Using plant functional traits to understand the landscape distribution of multiple ecosystem services. Journal of Ecology, 99(1): 135-147.

Lavorel S. 2013. Plant functional effects on ecosystem services. Journal of Ecology, 101(1): 4-8.

Li Q, Zhou D W, Jin Y H, et al. 2014. Effects of fencing on vegetation and soil restoration in a degraded alkaline grassland in northeast China. Journal of Arid Land, 6(4): 478-487.

Li S Y, Verburg P H, Lv S H, et al. 2012. Spatial analysis of the driving factors of grassland degradation under conditions of climate change and intensive use in Inner Mongolia, China. Regional Environmental Change, 12(3): 461-474.

Li X L, Wu Z N, Liu Z Y, et al. 2015a. Contrasting effects of long-term grazing and clipping on plant morphological plasticity: Evidence from a rhizomatous grass. PLoS ONE, 10(10): e0141055, doi: 10.1371/journal.pone.0141055.

Li X L, Liu Z Y, Wang Z, et al. 2015b. Pathways of Leymus chinensis individual aboveground biomass decline in natural semiarid grassland induced by overgrazing: A study at the plant functional trait scale. PLoS ONE, 10(5): e0124443, doi: 10.1371/journal.pone.0124443.

Makkonen M, Berg M P, Handa I T, et al. 2012. Highly consistent effects of plant litter identity and functional traits on decomposition across a latitudinal gradient. Ecology Letters, 15(9): 1033-1041.

McIntire E J B, Hik D S. 2002. Grazing history versus current grazing: leaf demography and compensatory growth of three alpine plants in response to a native herbivore (Ochotona collaris). Journal of Ecology, 90(2): 348-359.

Middleton B A, Holsten B, Van Diggelen R. 2006. Biodiversity management of fens and fen meadows by grazing, cutting and burning. Applied Vegetation Science, 9(2): 307-316.

Milchunas D G, Vandever M W. 2013. Grazing effects on aboveground primary production and root biomass of early-seral, mid-seral, and undisturbed semiarid grassland. Journal of Arid Environments, 92: 81-88.

Moreno García C A, Schellberg J, Ewert F, et al. 2014. Response of community-aggregated plant functional traits along grazing gradients: insights from African semi-arid grasslands. Applied Vegetation Science, 17(3): 470-481.

Moreno L, Bertiller M B. 2015. Phenotypic plasticity of morpho-chemical traits of perennial grasses from contrasting environments of arid Patagonia. Journal of Arid Environments, 116: 96-102.

Niklas K J, Cobb E D. 2006. Biomass partitioning and leaf N, P-stoichiometry: comparisons between tree and herbaceous current-year shoots. Plant, Cell and Environment, 29(11): 2030-2042

Niu K C, Choler P, Zhao B B, et al. 2009. The allometry of reproductive biomass in response to land use in Tibetan alpine grasslands. Functional Ecology, 23(2): 274-283.

Schrama M J J, Cordlandwehr V, Visser E J W, et al. 2013. Grassland cutting regimes affect soil properties, and consequently vegetation composition and belowground plant traits. Plant and Soil, 366(1-2): 401-413.

Thorne M A, Frank D A. 2009. The effects of clipping and soil moisture on leaf and root morphology and root respiration in two temperate and two tropical grasses. Plant Ecology, 200(2): 205-215.

Van Bodegom P M, Douma J C, Witte J P M, et al. 2012. Going beyond limitations of plant functional types when predicting global ecosystem-atmosphere fluxes: Exploring the merits of traits-based approaches. Global Ecology and Biogeography, 21(6): 625-636.

Warton D I, Duursma R A, Falster D S, et al. 2012. Smatr 3-an R package for estimation and inference about allometric lines. Methods in Ecology and Evolution, 3(2): 257-259.

Wu Z Y. 1980. Vegetation of China. Beijing: Science Press. (in Chinese)

Xu X, Sherry R A, Niu S L, et al. 2013. Net primary productivity and rain-use efficiency as affected by warming, altered precipitation, and clipping in a mixed-grass prairie. Global Change Biology, 19(9): 2753-2764.

Zheng S X, Ren H Y, Lan Z C, et al. 2010. Effects of grazing on leaf traits and ecosystem functioning in Inner Mongolia grasslands: Scaling from species to community. Biogeosciences, 7(3): 1117-1132.

Zhou X H, Wan S Q, Luo Y Q. 2007. Source components and interannual variability of soil $\mathrm{CO}_{2}$ efflux under experimental warming and clipping in a grassland ecosystem. Global Change Biology, 13(4): 761-775. 